\title{
Space science is a winner
}

\section{Tokyo}

JAPAN's space scientists and astronomers find favour in the 1990 budget request just submitted by the Ministry of Education, Science and Culture (MESC) to the Ministry of Finance. Although total funds for space science are reduced, the budget is full of small but significant requests for 'seed money' to begin major new projects in space science and astronomy. Global environment research also gets a boost.

The ministry's budget will not be finalized until the end of the year but is likely to pass the Ministry of Finance without major amendments.

One of the most significant items in the budget is a tiny request of $¥ 14$ million $(\$ 100,000)$ in preparatory funds for a 7.5 metre infrared telescope to be built at Mauna Kea in Hawaii by the National Astronomical Observatory. The observatory, which until recently was part of

\begin{tabular}{|c|c|c|}
\hline \multicolumn{3}{|c|}{$\begin{array}{l}1980 \text { Science budget request for } \\
\text { Ministry of Education, Science and } \\
\text { Culture }\end{array}$} \\
\hline & $\begin{array}{l}\text { thousand } \\
\text { million } \\
\text { yen }\end{array}$ & $\begin{array}{c}\text { (\% change } \\
\text { from } \\
1989)\end{array}$ \\
\hline $\begin{array}{l}\text { Grants-in-aid of } \\
\text { research }\end{array}$ & 56.0 & $(+6.4)$ \\
\hline $\begin{array}{l}\text { Government/lndustry } \\
\text { research }\end{array}$ & 11.4 & $(+10.7)$ \\
\hline Donations from Industry & 39.2 & $(+18.0)$ \\
\hline Research fellowships & 2.2 & $(+14.1)$ \\
\hline Nuclear fusion & 9.0 & $(+4.8)$ \\
\hline $\begin{array}{l}\text { Accelerator physics } \\
\text { (TRISTAN) }\end{array}$ & 16.4 & $(+3.2)$ \\
\hline Space science & 18.3 & $(-12.3)$ \\
\hline Astronomy & 0.9 & - \\
\hline Environment & 4.0 & $(+32.2)$ \\
\hline Earth Science & 2.3 & $(+8.8)$ \\
\hline Antarctic research & 5.1 & $(+73.1)$ \\
\hline International exchange & 6.6 & $(+12.4)$ \\
\hline
\end{tabular}

Tokyo University, has been trying to win support for the telescope for years (see Nature, 311, 5; 1984).

The telescope will have a very high resolving power (about 0.1 arc seconds) and wide field of view, making it ideal for the study of the processes of formation of stars, planets and galaxies. The total cost of the telescope and related facilities is expected to be about $¥ 45,000$ million (\$312 million), more than twice the amount estimated in 1984 when plans for the telescope were first made public.

Also hidden away in the budget request is a small allocation for the development of a new solid fuel rocket for the Institute of Space and Astronautical Science (ISAS). The rocket will have about three times the power of the institute's present biggest rocket the MU-3SII and will cost about $\$ 150$ million to develop. One of its first missions will be to launch a radiotelescope satellite (see page 92). And the budget for space science will rise after
1990 as development costs of the rocket and satellite increase.

Radioastronomy gets another big boost with a request for $¥ 845$ million (\$6 million) to build a heliograph at the Nobeyama Radio Observatory of the National Astronomical Observatory. The heliograph will consist of a T-shaped array of $7680-\mathrm{cm}$ parabolic antennas. It will be completed in two years at a total cost of about $¥ 1,900$ million ( $\$ 13$ million) and will observe solar flares during the next solar maximum in conjunction with the solar observation satellite Solar-A, which is scheduled to be launched by ISAS in 1991.

The global environment features prominently in MESC's budget request as it did in the already-released budget requests of other government ministries and agencies (see Nature 341, 4; 1989). And, similarly, some of the money is to be used to establish new research centres.

The Research Institute of Atmospherics at Nagoya University will be reorganized into an institute provisionally named the Solar Earth Environment Research Institute at a cost of $\$ 1$ million ( $¥ 136$ million). The institute will study the inflow and outflow of energy and materials from the Earth and Sun and the effect of these fluxes on the global environment

A similar amount ( $¥ 224$ million) is requested to reorganize and rename the Sand Dune Research Institute of the University of Tottori. The revamped institute will broaden its horizons from the study of local sand dunes to research on the deserts of the world. And $¥ 26$ million is requested to establish an Arctic research centre at the National Institute of Polar Research.

Funds for joint international research on the global environment rise 10 per cent above this year's level to $¥ 3,239$ million (\$22.5 million). Extra backing goes to joint research on the Arctic environment in collaboration with the United States, Norway and other countries. Antarctic research also receives a huge increase (73 per cent) to $¥ 5,069$ million ( $\$ 35$ million) but much of the extra money is a one-time allocation for the purchase of a ship-borne helicopter.

David Swinbanks

- "Donations from industry", one of the biggest items in the budget request, are funds donated under a scheme established by MESC in 1983. Such donations are the fastest growing source of support for university researchers and are expected to reach nearly $¥ 40,000$ million ( $\$ 280$ million) in fiscal 1990. The government's contribution - $¥ 11,400$ million $(\$ 80$ million) in fiscal 1990 ("government/ industry research" in table) - has also grown rapidly, and the total budget for the scheme now almost matches MESC's budget for research grants.

\section{UK physicians demand action}

\section{London}

ADVANCES in methods for genetic screening and prenatal diagnosis should be available to all couples wishing to have children, the British Royal College of Physicians (RCP) has recommended. Education about genetics should begin at school, should be a part of the medical school curriculum and should also become a part of clinical practice.

In a report published on 7 September, the RCP claims that many British couples are denied access to up-to-date screening techniques and prenatal diagnosis and that the availability of these tests varies four-fold between different health authorities, the administrative organs of the National Health Service. The report says that the test for spina bifida, available since the $1970 \mathrm{~s}$, is offered to only 70 per cent of women at risk, while amniocentesis for Down's syndrome is available at only 12 hospitals in Britain.

The report recommends that a nationwide screening and prenatal diagnosis scheme should be established, which would become an intrinsic part of maternal health care. Professor Martin Bobrow, a clinical geneticist at Guy's Hospital Medical School who helped to write the report, said a comprehensive screening and back-up system of diagnosis could prevent the birth of 2,000 severely handicapped babies a year. The RCP concludes, after a cost-benefit analysis of the scheme, that "if the costs of the whole programme were aggregated, it is cheaper to screen and counsel the whole population than it is to treat affected childen who would otherwise be born to unprepared couples". The cost of a test is a few pounds, the cost of caring for a severely handicapped child is about $£ 10,000$ a year. Dr Margaret Turner-Warwick, RCP president, said short-term budgetary considerations meant that health authorities did not think in terms of long-term saving.

Sir Raymond Hoffenberg, a past RCP president and a member of the working party, said an integral part of the plan was to improve education. Many women were not offered tests simply because general practitioners and hospital consultants were unaware of what was available. The report says a designated co-ordinator should be responsible for organizing delivery of both specialist and community genetic services in each region.

A code of practice should be drawn up to tackle the inevitable ethical problems involved. Bobrow said prenatal diagnosis would not be used for positive eugenic policy, but to enable individuals to make informed decisions about their lives based on the fullest possible knowledge. 